\title{
The Traditional Courts Bill
}

\section{A silent coup?}

\section{NOMBONISO GASA*}

chisana@wol.co.za

This article calls into question the representation of traditional governance and customary law that underpins the Traditional Courts Bill (B15-2008)(TCB). It argues that the Bill presents a flawed view of traditional custom and practice by, amongst other things, failing to recognise the changing nature of custom and cultural practice. In so doing the Bill provides a legal basis upon which prejudice and discriminatory practices may be entrenched. The article argues that African cultures have always valued individual rights and choices, and affirmed these as integral to each individual being part of a community. This is in no way represented in the Bill. The author argues that the TCB has not only disregarded five years of work of the SALRC, funded by tax-payers, but also proposes a system that contradicts the Constitution.

Freedom from all forms of bondage, subjugation and prejudice formed the cornerstone of liberation from apartheid. The understanding of freedom as fundamental to our existence as individuals and communities in a democratic state has led us to explore our understandings of different forms of colonial and apartheid domination.

These were more than formal processes; they were at the heart of defining what it means to be human. Of course the experience of apartheid took different forms and impacted differently on various sectors of society. But on the whole, it sought to manipulate and even destroy our common humanity as South Africans.

It is against the background of total subjugation of individuals and communities in cultural, political, spiritual and economic spheres, knowledge systems, and educational processes, that the current debate on restoring the dignity of African cultural practices, belief systems and customary law must be located.

* Independent researcher, columnist, writer, essayist and analyst: Gender, politics and cultural issues.
How do these coexist with the South African Constitution, which recognises and respects African customs, beliefs as well as various forms of leadership on the one hand, and is committed to building a secular society that accords equal rights and dignity to all its citizens on the other? What would be the best form of affirming African customary law while recognising that no community, including Africans, and cultural and religious groupings such as Muslims, Jews and Christians, exist in isolation? And given the legal supremacy of the Constitution, what happens when it conflicts with cultural practices, and religious and other identities? What is needed is to find a balance that builds harmony and contributes to the peaceful coexistence of all South Africans. Central to this balancing is the need to act without compromising the supremacy of the Constitution as the highest law of the land.

African people's ways of existence, including cultural practices and belief systems, were denigrated and almost annihilated under apartheid. The restoration of those marginalised cultural practices forms part of South Africa's nation-building project and needs to be alive to 
the contradictions that have always existed within these cultures and communities.

For example, understanding and probing the meaning of power, and the epistemological assumptions that underpinned the colonial project, is central to unifying as well as restoring the dignity of all South African people. In this context, African customary law needs to be viewed as an intrinsic but complex part of a democratic state based on diverse cultural experiences and identities.

Culture needs to be understood as a fluid pattern of social relations, construction of identities and communal existence. At the core of African customary practices and cultural philosophies is the belief that umntu ngumntu ngabantu - a person is a person because of others. The codependency between individual existence and collective or communal existence cannot be overemphasised. But here is the critical component which is often obliterated: umntu ngumntu ngabantu also affirms the importance of the individual, because without that individual who is indeed affirmed and enriched by interaction with other people, the adage simply cannot exist.

This article argues that African cultures have always valued individual rights and choices, and affirmed these as integral to each individual being part of a community. There is no individual/ community dichotomy. Recognition of the individual is not a foreign concept, but deeply embedded in cosmological questions. For example, many African belief systems hold: 'if you spit in the face of the daughter of the Y clan that defiles not only the individual but his or her ancestors and those from whom she has come'. Whilst the individual is connected to a larger community, s/he is respected in her own right and for no other reason but simply that s/he is human, deserving dignity and fair treatment and respect.

Individual rights and responsibilities are the cornerstone of community existence. In various idioms we find expressions rich in affirming the individual without erasing other human beings or the community. In isiXhosa, it is said akukho nkwal'ephandel 'enye, ephandel 'enye yenethole 'no pheasant scratches for another, the one that does so, does first for its offspring'. In short, the primary responsibility of any members of a community is to address their responsibilities and the needs of their offspring and those dependent on them in order to be productive members of the community.

\section{LOCATING THE TCB}

It must be considered whether the TCB may entrench distorted meanings of community and notions of belonging. Factors to take into account are the different expressions and rituals that recognise the individual and the protection of individual dignity, as well as the responsibility and place of community and customary systems of governance.

Despite a commitment to move away from apartheid-era (pre-liberation) readings and interpretations of 'traditional leadership', customary law and practices, and cultural identities, the TCB, like so many other legislative attempts to address this complex area, falls into the same traps of colonial and apartheid sensibilities, boundary formation and definitions. Many debates, literature and policy processes that claim to restore the dignity of African cultural and customary systems and leadership fall into essentialist representation, treating these dynamic processes as static.

African cultures, like any others, are complex and dialectical, and contradictory in how they have unfolded, grown and continue to live in multiple relationships, internally and externally.

Regrettably, the continued romanticisation of African cultural practices and identities as immemorial and unchanging leads to their being seen as exotic. This interpretation is of course based mainly on scholarship with vested interests relating to power and privilege, as well as a need to present static notions of African systems as humane and without any contradictions or inequalities. 
Recognition of these inequalities and contradictions does not detract from the most valuable and positive aspects of what have been continually evolving African cultural processes and understandings. In any cultural milieu, there is that which is empowering and restrictive, enabling and disabling. As society develops we have to interrogate what is emancipatory and what hinders self-realisation in these cultural worlds. In his foreword to Nkosi Phathekile Holomisa's book, According to Tradition: A cultural perspective on current affairs, Sonwabile Mancotywa writes, 'Over and above everything else our traditional leaders continue to be custodians of our rich and diverse cultural heritage. Indeed if it were not for their wisdom and intrepid spirit to rise above colonial structures, as a nation we would be faced with identity crises, without any trace of our source of origin or an anchor to our African roots...'.

Mancotywa's words point to one of the critical dangers that African cultural systems encounter, a narrative based on a distortion of historical legacies. In reality, 'traditional leaders' are not custodians of culture in the African cultural milieu. People of different ranks and stature are custodians and repositories of knowledge, customs and practices. It is these people - the bearers of knowledge and wisdom of their people - upon whom Africans have entrusted these responsibilities and roles since pre-colonial times. Izanusi, in a Zulu cultural context, are appealed to as people whose responsibility is not born of inherited titles but through training, learning and investing time to protect and enhance the knowledge systems and diffuse these.

In times of crises or where complex issues have to be interpreted, izanusi are often called, either to work as individuals or as part of a team of people of the same rank and knowledge, to guide conversations and to look deeper into those complex issues.

Among the Yoruba in West Africa there is a saying, 'when a griot dies, a whole library is lost'. This is in recognition of other spaces where knowledge and wisdom is found. The griot's role in the historical record of his or her people is as undisputed as that of elders in our families from whom we learn of our heritage, lineage and identity.

But the griots and izanusi have never pretended to be bearers of knowledge that is unchanging. They survived and remained relevant because they learnt as they taught. In the African cultural milieu, a custodian does not necessarily have to know everything and have the last word all the time.

Mancotywa's foreword is in line with the TCB in its concentration and centralisation of power, knowledge and 'wisdom' in 'traditional leaders' in a single individual, the presiding officer. This displaces the role of family elders, who are critical in dispute resolution, in assisting young people to know their lineage and helping them to be rooted and anchored in their identity. ${ }^{1}$ There is a marked and fundamental difference between the TCB and the Bill put forward by the South African Law Reform Commission (SALRC). The SALRC version of the Bill recognises the multi-centred layers of the customary court system. Thus, it proposes a flexible system which accommodates these different levels of operation.

Recognition of a single court within the ambit of customary law in a 'traditional community' and the promotion of centralised power are in fact inimical to the heritage that the TCB claims to affirm. Ordinarily, when a matter comes to this level of court in a customary system, there are a range of steps that have already occurred (see also Sindiso Mnisi's concluding article in this edition of $S A C Q$ ). These findings are placed before the court as a narrative of the process, to ensure that no significant role player will feel excluded or undermined and to enable the court to determine the seriousness of the matter it confronts. At every stage of the hearing, such narrative is provided, supporting the court. Where necessary, those who are affected will come forward to attest to this as in 'sihleli siyinkundla yekhaya sathetha savana ukuba masidibane nosapho lwamathile siyisombulule le ngxaki njengabamelwane, kwacaca ukuba umhlaba uyenyukela, sagqitha ke njenge sithethe' (we sat as a family and decided to sit with 
the other family and agreed to resolved this matter as neighbours, it became clear that this is an uphill battle and thus concluded to go beyond that, according to practice....) Each stage verifies the participatory nature of the system and commitment to seek resolution as neighbours.

Gradually, a body of work, evidence, and thorny issues emerge, and often even the 'customary court' cannot make an instant pronouncement but will go outside the immediate royal family and seek advice from izanusi - the 'wise ones' based on their knowledge, skill and investment in their community.

Entrusting power and decision-making to one individual in the manner suggested in the TCB (section 4(i) and (ii)) violates the intention of such processes. ${ }^{2}$

Further, the SALRC Bill proposed that the 'customary courts' should comprise representatives of the community. It also proposed the inclusion of women as participants and representatives of community interests. These different stakeholders, whilst bound to operate within the 'customary law' system, would provide community participation and a bridge between the community and the customary courts.

The SALRC Bill also proposed that the participation of councillors be looked at and that government should develop policy in this regard. It is easy to understand why the SALRC did not make a clear recommendation on this as it is one of the hotly contested issues by 'traditional leaders', some of whom have been on record objecting to local government in 'traditional communities' and the role of councillors. Whilst the context of this is understood, it is not acceptable that the SALRC Bill and later the TCB have considered the voices of 'traditional leaders' as the most important in this debate.

There is no doubt that the procedures of community participation would have been highly contested both in terms of functioning as well as composition. Some customary practices to which the SALRC Bill referred prohibit women from direct participation in decision-making and even direct representation as complainants, defendants and advisors on complex issues. Whatever considerations informed the Department of Justice and Constitutional Development's approach, and the decision to drop the SARLC Bill and introduce the TCB, the primary and hegemonic voice of 'traditional' leaders is clear. It actively advances proposals, provisions and parameters that undermine some of the constitutional principles it sets as guidelines, and which it purports to respects and promote. It is also interesting to note that throughout the TCB all the proposals that were made by 'traditional leaders' are endorsed, and complex issues that were raised by communities and other stakeholders in the SALRC are ignored.

One such issue involves the notion of opting out. For example, section 20 (c) asserts that any person who:

having received a notice to attend court proceedings, without sufficient cause fails to attend at the time and place specified in the notice, or fails to remain in attendance until conclusion of the proceedings in question or until excused from further attendance by the presiding officer, is guilty of an offence or liable on conviction to a fine. ${ }^{3}$

The assertion of authority on grounds of jurisdictional boundaries is problematic, ahistorical, and contrary to customary systems and a long history of self-determination. This provision not only undermines the constitutional rights of citizens who live in areas demarcated as 'traditional communities', but it also seeks to impose a single identity and an interpretation of customary law that is inconsistent with the inherited and living law.

Some of the provisions in the TCB will suffocate the dynamism of those communities defined as 'traditional communities', and will impose cultural hegemony at the expense of peaceful coexistence. This may amount to cultural chauvinism. 
In some communities there are people of mixed religions and spiritual beliefs. For example, it is sometimes ruled that burials will not take place on a Sunday. This denies the right of those who cannot bury on Saturdays to practice their religion and belief systems freely. Should they be found to have disobeyed an order of the court, or disturbed communal harmony, some may elect not to present themselves to the 'traditional court' and thus opt out. In their eyes and world view, the 'customary court' may not or should not pronounce on their spirituality. By not giving them an opportunity to opt out, their constitutional right of worship is violated.

This example is made deliberately because it is perhaps the least contested. There are many less visible examples that may present complex issues and lead to conflict. This may be particularly so in communities of mixed 'cultural identity' where some clans may choose not to be subjected to the dominant customary law. These clans may have lived together for several generations but yet may have practices, including 'customary practices', that are not common between them. Refusing such people, and individual members of a community, space to opt out undermines their constitutional right and choices.

The refusal to give people an option to 'opt out' is an expression of the anxiety of 'traditional leaders' to avoid any potential undermining of their authority. It is revealing that 'traditional leaders' fear that their 'own' communities may not recognise their power. This points to the need for a debate on representation, legitimacy and confidence of communities in these institutions.

It is the notion of fixed, unchanging, African cultural homogeneity based on static boundaries and cultural identity that underpins all the laws and policies that are applicable in African customary law and systems in South Africa today. Ironically, the geographic boundaries for these laws are derived from the very laws that should be scrapped, such as the Black Authorities Act 68 of 1951 and the Black Administration Act 38 of 1927. They are ossified in a manner that is permanently scarring South Africa according to apartheid and colonial logic. This destroys any notion of a living customary law.

Alongside these apartheid geographic boundaries come a range of practices and authoritative systems that undermine the constitution and entrench inequality. For example, African 'customary' practices are said to be egalitarian and are largely so. Yet there are also fundamental contradictions and inequalities that often determine the status of a person within a pecking order and can be highly prejudicial. For those who come from small clans that have no status in the system, for those who do not have cattle or the means to assert their authority, for women and children, this system can be oppressive. It is therefore important that any process that seeks to affirm 'customary practices' also develops mechanisms to prevent abuse and prejudices that are visited upon South Africans, wherever they are.

The TCB has not only disregarded five years of work of the SALRC, funded by tax-payers, it also proposes a system that contradicts the Constitution.

\section{GENDER AND THE TCB}

Scholars who have written on gender have identified the obliteration of women as active agents of change with specific roles, identity and power in favour of the nation, which, more often than not, is based on a patriarchal framework and epistemology. This is a glaring point of departure in the TCB's presentation of 'traditional governance'. Even the schedule of cases that may be put forward in these courts unmasks the logic and rationale that the TCB tries to hide through its continuous reference to constitutional principles.

There is a glaring absence of crimes committed against women, including those that are already identified in the national legislation. For example, conjugal rape, incest, statutory rape (including that which takes place during the forced marriages of girls who are legal minors, 
ukuthwala), domestic violence and spousal abuse do not appear in the schedule. Thus these cannot be heard in the customary courts and yet they cannot go elsewhere because they fall within the 'traditional community'.

There is a double edged sword on gender in 'traditional courts'. It is doubtful whether inclusion of these crimes in the jurisdiction of such courts would be desirable for women, girls and some men who may experience genderbased violence and discrimination, including on grounds of sexuality and sexual identity.

Experience of what has been generally referred to as 'tribal courts' has shown indifference, inadequacy and downright hostility to people who speak of these crimes. On the other hand, exclusion of these crimes in the schedule of cases within the scope of the TCB creates another problem.

If people who live in the areas designated as 'traditional communities' cannot opt out and take the choice of using the magistrate's court, the family court or the equality court as their courts of first instance, these people are left without any access to justice.

Given this problem, it is apparent why the SALRC's version of the Bill proposed to exclude all matters pertaining to gender violence, discrimination, dissolution of marriage and sexual offences. However, given the strong opposition by some leading voices, especially among 'traditional leaders', it is clear that this is going to be an area of major contestation.

Excluding these issues must be met by recognition of citizens' inalienable right to opt out of the system.

The reality is that these courts are not sympathetic to the victims of these crimes, given the patriarchal framework in which they are located. That is not to say conventional courts do not present their own inadequacies. But they have the potential to offer women better access to justice because they are subject to the constitution and laws of the country.

\section{THE TCB AND ABUSE OF POWER}

There are very few South Africans, if any, who can argue that customary law bears no relevance today. Similarly, it is hard to imagine serious thinking South Africans disputing the relevance and importance of the institution of 'traditional' leadership, however constituted.

The TCB touches on an issue that is important not only to those for whom it is applicable, but brings up a central challenge to South Africa's emergence as a constitutional democracy. However, in its current form the TCB undermines the goal of restoring dignity to 'traditional leaders' and others who have been harmed, and reduces the meaning of freedom for rural Africans to the status of the subaltern.

To those who are familiar with the history of the institution of traditional leadership during colonial conquest and the apartheid era, this creates unfortunate continuities, including the possibility of the abuse of power. These communities are a significant part of the South African population; they include 17 to 18 million South Africans, according to some statistics. The TCB in its current form effectively disenfranchises these communities. While they can go through the formal processes of voting, what that means, particularly in relation to local government, clearly needs further probing. The Bill as it presently stands erodes local governance in a significant manner. Some of the tensions between local government and traditional institutions in South Africa are directly related to issues of land, identity, power and authority.

Consider this example: Mngqanga is a village in the surrounds of Lady Frere, which Rhodana under abaThembu baseRhode 'Traditional leadership' in the Eastern Cape. During the height of the rule of KD Matanzima, the people of Mngqanga decided to protest and defy the rule of the Transkei government, which was synonymous with being subjected to serf-like status. People had to work the fields of the Paramount Chief, pay lobolo for his many wives and undertake activities as part of the women of the Transkei National Independence Party (TNIP). 
Tired of the defiance and protestations of the people of Mngqanga, a scorched earth policy was applied in this rural community. Villagers woke up to find their homesteads and plains on fire. In the kraals, the trapped sheep and goats bleated and the cattle bellowed. Some houses caught fire and people lost not only their livestock, but also their homes and belongings. Word is said to have come from the abaThembu Royal palace in Qamata, zitshiswe ngamandla akomkhulu, (the destruction by fire was caused by the special powers of the royal house). The people of Mgqanga continue to live with the scars of this memory.

These people, and many others, we are now told, have trust in and a bond with their 'traditional leaders' that is born of common heritage. They watch and listen as others speak of the institution as their anchor and proud heritage.

Whilst the rest of South Africa went through the process of the Truth and Reconciliation Commission (TRC), not a word was said about the brutalities that were visited on these people and others all over South Africa. That silence remains even more problematic in the context of the powers given to 'traditional leaders' through the TLGFA and the proposed TCB. The recent hearings in parliament, where the TCB was discussed with people who came from rural communities all over South Africa, exposed some of the abuses that are taking place today, in the name of culture.

\section{CONCLUSION}

This article has asked whether we need the TCB in the form that it has taken. Does having this layer of courts actually make justice more accessible to poor people? Does restoring the dignity of customary law and affirmation of African cultural systems mean that South Africa must introduce 'traditional courts' with such sweeping powers? Is it in fact customary law and cultural heritage that is being affirmed?

The TCB in its current form is clearly concerned with affirming the power, status and standing of 'traditional leaders'. This Bill does this with little regard for the consequences of those who will not be able to avoid being trapped in this system.

It is revealing that the TCB makes no provision for members of the community to raise issues and concerns they may have about the behaviour of 'traditional leaders' and the 'traditional courts'. It does not deal with what happens when these communities are subjected to abuse. In this way the TCB fails to restore the dignity of 'customary law and systems'. Instead, in its current form, it presents a silent coup against hard won freedoms for all, including those who were dumped in the 'reserves' as sources of cheap labour.

The author is grateful to Raymond Suttner, for continued discussions on these and several other critical issues in our quest to build an equal, just and fair society based on sound constitutional principles and human dignity.

To comment on this article visit http://www.issafrica.org/sacq.php

\section{NOTES}

1. K Barber, I could Speak Until Tomorrow: Oriki, women and the past in a Yoruba Town, Edinburgh University Press, 1992.

2. Traditional Courts Bill (B15-2008).

3. TCB Section 20 (c). 